\title{
Exploration for Ability Improvement of Teachers in Universities and Colleges under the Background of "MOOC"
}

\author{
Zhen Zeng \\ Business School, Yunnan Normal University, Kunming, 650106, China
}

\begin{abstract}
Keywords: MOOC, Teachers in universities and colleges, Integrative competence, Innovation capability, English proficiency
\end{abstract}

\begin{abstract}
With strong global influence of "MOOC" and its great challenges to traditional teaching mode, this paper proposes to adapt in a better way to new international teaching means from the angle of teachers, so as to conform to the coming of "MOOC" age. To this end, teachers must improve their abilities, including integrative competence, innovation capacity and English proficiency. Only ability improvement can enable the teachers to play a better role in new teaching reform.
\end{abstract}

\section{Concept and Advantages of MOOC}

\section{Concept of MOOC}

MOOC refers to massive open online course. Anyone should have a computer for online registration so that he can enjoy, free of charge or under payment, online courses provided by star professors in famous Ivey League universities and top-ranking Chinese colleges and universities without any limitation of time and space. MOOC is characterized with openness, transparency and easy access to high quality educational resources, providing all persons with a new learning channel and a new learning pattern. Massive refers to the capacity of MOOC surpassing traditional face-to-face course. Hundreds of or even thousands of persons can participate into such course. Open refers to opening to global network. Online refers to the completion of all learning processes on the Internet. Course refers to the course taught in MOOC ${ }^{[1]}$. MOOC divides each course into several units and then into different knowledge nodes. After that, multimedia materials are used to vividly unscramble these knowledge nodes in 10-15 minutes by means of video. In the unscrambling process, knowledge point detection is designed. In class, the students need to answer small questions in the pop-up window from time to time, so as to test their mastering degree of the previous knowledge points. At the same time, each MOOC is provided with a discussion forum. In the learning process, any student can release his or her questions in the discussion forum and discuss online with other students or teachers. In this way, the students' questions can be promptly solved. After class, the students need to finish related homework \& paper and to participate into examinations. Both deadline of homework and examination should be finished within a certain period of time. No matter for homework or examination, the students will have three opportunities to make final adjustment to their answers. MOOC emphasizes the whole learning process of the students instead of learning result only. Therefore, MOOC brings forth the world a new vertical and dynamic course pattern integrating interactions between students and teachers and communication between different students.

\section{Advantages of MOOC}

\section{Interestingness of course}

Teaching videos of many MOOCs are represented by means of animation, visually giving people a new sense of feeling. At the same time, representation of knowledge points by means of animation will make knowledge points difficult to be understood in ordinary times to become more interesting and easier to be understood. Moreover, it is easier for the students to rapidly understand and master knowledge points under an easy and happy scene, for instance, the course set up by MIT for entrepreneurs: Entrepreneurship 101: Who is your customer? In this course, some knowledge points are unscrambled through the pattern of animation. In the whole process of knowledge reception, the 
students can easily and happily grasp knowledge. Moreover, it is easier to be deep-rooted for knowledge mastered by the students under such situation.

Active social contact elements

The function of social contact is one function of network. People can communicate with others in various places in the world through the Internet. The platform of MOOC took this point into full consideration, and introduced the elements of social contact into this course.

Flexibility of course

Registration of MOOC is almost free from any limitation. As long as the participator has a networked computer and an email, the whole registration process can be finished within several minutes. After the completion of successful registration, the participator can browse all open courses from various colleges and universities in the world on the platform of MOOC. If the participator is interested in a certain course, he/ she can register this course prior to the commencement of it. Moreover, the participator can also browse the outline, mode of examination and type of obtained certificate related to this course. After the commencement of the course, the participator can learn at any time and place. As long as the participator submits his/ her homework and examination within the deadline, he/ she can successfully finish his/ her studies.

Economical efficiency and recognition degree of course

The biggest advantage of MOOC is that is of free of charge. Registration of MOOC platform is free of charge, and registration of one course is also free of charge. Moreover, obtainment of Certificate of Accomplishment is still free of charge. Certainly, the students need to charge, if they want to obtain Certificate of Achievement. However, such charge will not be too high. Therefore, economical efficiency of MOOC is of huge attraction for the learners.

\section{Challenges of MOOC for Ability of Teachers in Colleges and Universities}

\section{Teachers' integrative competence}

Teachers' comprehensive knowledge level

A course popular among the students inevitably gives expression to a teacher's comprehensive knowledge level. In the present stage, Chinese teachers have two aspects of difference when compared with those ones in American colleges and universities with respect to knowledge structure: firstly, Chinese teachers in colleges and universities are not enough in the scope of knowledge. Besides, they lack systematic training of pedagogy knowledge, and have less understanding of knowledge about pedagogy, psychology and teaching methodology. Secondly, Chinese teachers in colleges and universities are not enough in deep understanding of knowledge. Due to shortage of practical knowledge, fewer teachers have enterprise work experiences before being engaged in teaching. After being engaged in teaching, these teachers lack social practice opportunities, and are obviously insufficient in practical experience and practical knowledge, seriously influencing digestion and deep understanding of knowledge ${ }^{[2]}$.

Teachers' information technology level

At first, the coming of MOOC should take teachers' information technology level into consideration. At present, the information technology level of most teachers in colleges and universities is only confined to making PPTs and displaying these PPTs in class. Fewer teachers can flexibly apply MOOC technology in development of course resources. From the perspective of design and making of the whole MOOC, teachers should present the course through various modes such as micro-video, micro-audio, PPT display and animation. Moreover, many small questions and small quizzes should also be designed in different stages. At the same time, the teachers should interact with the students in the discussion forum and the MOOC community. All these factors require the teachers to have a certain information technology level. Therefore, further improvement must be made to the information technology level of teachers. 


\section{Teachers' innovation capability}

Teachers' innovation capability is mainly reflected in innovative thinking and innovative knowledge. In recently 10 years, there is almost no great development for ideological education pattern of teachers in colleges and universities. Such pattern is also limited to theoretical learning and infusion. The education content is modeled, unchanged and old-fashioned. The learning style doesn't get rid of mechanical teaching and stereotype. Such ideological education pattern seriously limited development of teachers' innovative thinking. Under such pattern, the teachers cannot expand their thought or learn about new thinking mode. However, the birth of MOOC requires the teachers to have new thinking. It needs innovative elements from conception, design and final completion of a course. Only innovation can design unique courses. Therefore, MOOC brings forth huge challenges to teachers' thinking innovation.

\section{Teachers' English proficiency}

MOOC was sourced from western countries. At present, English is taken as main language for most courses released on the largest MOOC platforms in the world, i.e. Udacity, Coursera and edX. Well-known courses of world famous colleges and universities in the world are released in English. Moreover, all exercises, homework and tests are finished in English. Therefore, teachers must master and apply English to some extent, so as to learn MOOC experiences from western countries. To be listed among international MOOCs, to use which language is a practical issue for urgent solution in China. Here, the issue of language covers two aspects: the first one is the issue of the language used by teachers. In other words, how many Chinese teachers can teach in English and make and use MOOCs? The second one is: to use which language to express the contents related to MOOCs is more beneficial? MOOC audiences are from various countries and regions all over the world. Due to language, regional and cultural difference, it is likely to cause understanding deviation or even misunderstanding, if it only replies on translation [3]. Therefore, use of English may represent the general trend, if the teachers want to learn MOOC experiences from western countries or even compete with MOOC teachers in famous international colleges and universities in the future.

\section{Countermeasures for MOOC Challenges}

\section{Comprehensively improve teachers' integrative competence}

\section{Improve teachers' comprehensive knowledge level}

With continuous development of information age, MOOC requires massive innovation to integrative application of multi-disciplinary knowledge. Therefore, teachers should enrich their knowledge level and keep continuously learning, making their knowledge level to have certain width and depth. Moreover, teachers should also positively participate in various academic lectures and continuously perfect and update their knowledge. At the same time, schools can also allow the teachers to share their teaching methods and experiences by holding teaching research activities in various types.

Improve teachers' information technology level

MOOC is a kind of reform to teaching mode developed based on modern information technology and network platform. Information technology is served as an important support for development of MOOC teaching. In the process of course development and maintenance, professional technicians can be employed to provide technical supports. However, they can only provide technical supports, and cannot realize new transformation of teaching concept from the perspective of reform to technical means. Only teachers can take advanced education and teaching philosophies into practice. Therefore, it is imperative for improvement to teachers' information technology level. Teachers should actively participate in research and studies or training activities related to MOOC universal knowledge and information technology, and learn about related information technologies by virtue of books, references and MOOC platforms. Meanwhile, schools can regularly organize teaching workshops, allow relevant professional technicians to teach teachers information technology knowledge, 
evaluate the training effects, and give guidance to training works submitted by different teachers by means of excellent work exhibition \& evaluation or comments. Moreover, schools can also organize MOOC teaching competitions in various types, allowing the teaching to really apply video clip, animation, courseware insertion, online operation and other technologies into the courses. After continuous practices, teachers will naturally apply these technologies into relevant courses. In return, these technologies will become productive forces of teaching reform.

\section{Continuously dig teachers' innovation capacity}

MOOC is a kind of new teaching method and teaching mode. Teachers cannot follow old teaching philosophies to treat MOOC. To conform to the development of MOOC, teachers must take an unprecedented concept reform, learn about how to expand their horizon and open their train of thought, continuously accept new things and objects, learn about new teaching ideas and teaching modes, and abandon old-fashioned dogmatization and stereotype. In the study process, teachers should also continuously explore for and discover new things and objects, learn about how to treat and analyze issues from different angles of view, and cultivate their innovative thinking. Design of MOOCs requires innovation to thinking. Only MOOCs designed by new and unique concepts will be appreciated by the students. Moreover, there should also have different innovation points at the level of knowledge. Teachers should continuously learn and explore for luminous points of original knowledge, integrate and apply these luminous points, and create new knowledge points. New design thought and new knowledge points will become a prefect MOOC. Certainly, these new elements require teachers to continuously learn, discover and comprehend in the teaching process. Therefore, MOOC proposed high requirements for teachers' innovation capability.

\section{Comprehensively improve teachers' English proficiency}

Obviously, general trend of MOOC is representation of international education. Teachers should learn from famous teachers in famous international colleges and universities, and absorb their teaching experiences. All learning processes must take English as the medium. At the same time, teachers also need to complete with international language - English, so as to introduce their MOOCs to the world. MOOC teachers can utilize professionals' subtitle translation to help the students to understand their classroom explanation. However, certain English application capacity is required by classroom discussion, homework, exercises, test completion and communication \& interaction between teachers and students. Moreover, these interactive links are just the most, critical and innovative ones in MOOCs. Therefore, enough attention and great improvement should be made to teachers' English proficiency. In the learning process at ordinary times, it is necessary for teachers to cultivate their habits of reading English materials, and mastering and flexibly applying professional English vocabularies they teach. At the same time, teachers should also collect English wording modes used by famous teachers in famous international colleges and universities, and attempt to apply these modes in their classroom teaching. Furthermore, teachers should also cultivate their English application habits at ordinary times, gradually expand from life to classroom, and cultivate the process of English thinking. To be integrated with international MOOCs, Chinese MOOC must adapt to international common language environment. Attention must be paid to English proficiency of Chinese teachers.

\section{Conclusion}

For world education, MOOC is a brand new educational pattern. With the features of creativity, flexibility and economical efficiency, MOOC spreads all over the world, and provides the people with more convenient opportunities. Moreover, MOOC enjoys high-quality teaching resources with low costs. Openness of MOOC won wide attention of the educatees. At the same time, it also aroused high attention of the educators. MOOC proposed higher requirements for future capability of teachers. To make the most of this new educational pattern, teachers must make continuous perfection to their comprehensive competence, improve their comprehensive knowledge level and information 
technology level, open their space of thinking, and cultivate the ability of innovative thinking and innovative knowledge. At the same time, teachers should also comprehensively improve their ability to apply international general language - English. Only through continuous studies and self-improvement, teachers can really adapt to the new educational environment and educational pattern brought forth by MOOC and give full play o the function of MOOC.

\section{References}

[1] Wu Aihua, Advantages \& Disadvantages of MOOCs and Its Influence on College Education, Journal of Academic Library and Information Science, 2014, (32): 125-128;

[2] Li Xiaodong, Challenges of "MOOC" for Teaching Ability of Teachers in Colleges and Universities and Relevant Countermeasures, Journal of Nanjing University of Science and Technology (Social Sciences Edition), 2014, (27): 89-92;

[3] Guo Yingjian, Future of "MOOC" and Higher Education in China, Journal of Higher Education Management, 2014, (8): 29-33 